\title{
The NAC transcription factor family in maritime pine (Pinus Pinaster): molecular regulation of two genes involved in stress responses
}

\author{
Ma Belén Pascual, Francisco M. Cánovas and Concepción Ávila*
}

\begin{abstract}
Background: NAC transcription factors comprise a large plant-specific gene family involved in the regulation of diverse biological processes. Despite the growing number of studies on NAC transcription factors in various species, little information is available about this family in conifers. The goal of this study was to identify the NAC transcription family in maritime pine (Pinus pinaster), to characterize ATAF-like genes in response to various stresses and to study their molecular regulation.

Methods: We have isolated two maritime pine NAC genes and using a transient expression assay in N. benthamiana leaves estudied the promoter jasmonate response.

Results: In this study, we identified 37 NAC genes from maritime pine and classified them into six main subfamilies. The largest group includes 12 sequences corresponding to stress-related genes. Two of these NAC genes, PpNAC2 and PpNAC3, were isolated and their expression profiles were examined at various developmental stages and in response to various types of stress. The expression of both genes was strongly induced by methyl jasmonate (MeJA), mechanical wounding, and high salinity. The promoter regions of these genes were shown to contain cis-elements involved in the stress response and plant hormonal regulation, including E-boxes, which are commonly found in the promoters of genes that respond to jasmonate, and binding sites for bHLH proteins. Using a transient expression assay in $N$. benthamiana leaves, we found that the promoter of PpNAC3 was rapidly induced upon MeJA treatment, while this response disappeared in plants in which the transcription factor NbbHLH2 was silenced.
\end{abstract}

Conclusion: Our results suggest that PpNAC2 and PpNAC3 encode stress-responsive NAC transcription factors involved in the jasmonate response in pine. Furthermore, these data also suggest that the jasmonate signaling pathway is conserved between angiosperms and gymnosperms. These findings may be useful for engineering stress tolerance in pine via biotechnological approaches.

Keywords: Pinus pinaster, NAC gene family, Stress, Methyl jasmonate, Promoter

\section{Background}

Conifers are the most important group of gymnosperms, dominating large ecosystems in the Northern Hemisphere, and they are also of great economic importance, as they are intensively used for timber, fuelwood, resins and paper production [1]. During millions of years of co-existence with changing environmental conditions, competing plants, potential pests and foraging animals, conifers have evolved

\footnotetext{
*Correspondence: cavila@uma.es

Departamento de Biología Molecular y Bioquímica, Facultad de Ciencias, Campus Universitario de Teatinos, Universidad de Málaga, 29071 Málaga, Spain
}

potent and effective defense mechanisms. These mechanisms include structural, morphological or physical barriers, such as resin canals, calcium oxalate structures, sclereid cells and lignin, and/or chemical defences, which include the production of phenolics or volatile and non-volatile terpenoid compounds [2]. In previous decades, it was discovered that several plant phytohormones such as jasmonic acid (JA), ethylene (ET) and salicylic acid (SA) are involved in complex signalling cascades and in the synthesis of chemical defenses [3]. In particular, the Me-JA pathway has been found to be closely related to the wounding response 
to defoliating caterpillars, budworms and bark beetles [4-6]. In contrast to our detailed knowledge of the structures and chemical response related to stress, there is little information on the molecular mechanisms that enable plants to cope with environmental changes.

Maritime pine (Pinus pinaster Aiton) is particularly tolerant to abiotic stresses, displaying relatively high levels of intraspecific variability [7]. Maritime pine is also used as a model tree for conifer genomic research in Europe [8, 9] and the emergence of next-generation sequencing (NGS) has facilitated the de novo assembly of the transcriptome [10]. Sequencing data are available at SustainpineDB (http://www.scbi.uma.es/sustainpinedb/sessions/new).

A total of 877 transcription factors (TF) distributed into 30 families on the basis of conserved structural domains involved in DNA binding were identified in the maritime pine transcriptome [10]. The number of TF in maritime pine is similar to that previously reported for white spruce [11] but smaller than that reported for angiosperm species [10].

Regulation of gene expression plays a fundamental role in plant response to environmental stimuli. Recently accumulated evidence demonstrates that numerous families of TF, including the DREB, bZIP, MYB, zinc-finger, WRKY and NAC families, directly or indirectly regulate plant defenses and stress responses [12-18].

The NAC family is one of the largest plant-specific transcription factor families and is represented by 105 genes in Arabidopsis, 140 in rice, 110 in potato, 163 in poplar and 32 in white spruce. NAC proteins have a highly conserved $\mathrm{N}$ terminal DNA-binding domain comprising nearly 160 amino acid residues divided into five subdomains (A-E). The function of the NAC domain has been associated with nuclear localization, DNA binding and the formation of homo or heterodimers with other NAC domaincontaining proteins [19]. In contrast, the C-terminal region is highly divergent and contains a transcriptional regulatory domain [20]. The NAC factors regulate the expression of genes involved in processes such as shoot apical meristem development [21-23], floral morphogenesis [22, 24], lateral root development [25], leaf senescence $[26,27]$, regulation of cell cycle $[28,29]$, hormone signaling $[25,28,30,31]$, grain nutrient remobilization [32], xylogenesis, fiber development and wood formation [33-35]. NAC proteins also participate in plant responses to abiotic and biotic stresses [36, 37].

Several NAC proteins have been characterized in Arabidopsis, rice, soybean and cotton and have the potential to improve biotic and abiotic stress tolerance in plants. The overexpression of ANAC019, ANAC055 and RD26 (ANAC072) in Arabidopsis upregulated the expression of stress-inducible genes and improved the drought and salt tolerance of plants [38]. ATAF1 and ATAF2 in Arabidopsis, and HvNAC6 in barley play important roles in response to drought and pathogen stresses [31, 39-41]. ATAF1 acts as a negative regulator of $\mathrm{ABA}$ signaling but induces MeJA/ ET-associated defense signaling marker genes [31]. Conversely, ATAF2 expression is induced by dehydration, MeJA and SA, independently of ABA [40]. In rice, the overexpression of OsNAC1 and OsNAC5 enhances drought and salt tolerance and grain yield under field conditions [42, 43].

The structural characterization of members of the family of NAC transcription factors in angiosperms has greatly increased in past few years; however, the functions of most of most of these TF remain unknown. Limited information is available regarding NAC proteins in gymnosperms [23, 44]. In this study, we identified a total of 37 NAC domaincontaining TF in $P$. pinaster. Detailed analyses, including those of sequence phylogeny, conserved motifs and promoter analysis were performed. Furthermore, we have analyzed the expression patterns of two $P$. pinaster NAC genes, $P p N A C 2$ and $P p N A C 3$, which clustered with Arabidopsis ATAF1 and ATAF2 genes. We have identified its responses to treatments with high salinity, low temperature, wounding, MeJA and ABA. Both genes were rapidly and strongly induced upon MeJA treatment and/or wounding.

Furthermore, we performed in silico and in vivo analyses of the PpNAC3 regulatory region. In a transient expression approach using Nicotiana benthamiana leaves, the expression of PpNAC3 was regulated by bHLH MYC jasmonateresponsive transcription factors. This suggests a conserved mechanism in two phylogenetically distant species.

\section{Results}

\section{Identification and phylogenetic analysis of members of the NAC family}

The conserved DNA-binding domain of known NAC proteins was used as a query to identify the $N A C$ genes in the maritime pine database (SustainpineDB). A total of $37 \mathrm{pu}-$ tative $N A C$ genes were identified. We have annotated all the NAC domain-encoding genes as PpNACxx, where Pp is the species initials (Pinus pinaster) and $\mathrm{xx}$ is the number given in the ordered identification in the SustainpineDB.

The identified NAC genes in $P$. pinaster encode proteins with an average of 409 amino acids. Detailed information about the pine NAC genes identified in the present study, including accession numbers, similarities to the Arabidopsis putative orthologues, and the protein sequences, is provided in Additional file 1.

The program Clustal X version 1.83 was used for multiple sequence alignments of the protein sequences of $P$. pinaster. The results indicated that the $P$. pinaster NAC family can be classified into two groups, based on similarities in the structure of the DNA-binding domain: Group I, which could be subdivided into five clusters, and Group II, composed of a single cluster of five NAC proteins (Fig. 1).

To further study the diversification of the NAC family in pine, we predicted conserved putative motifs using 


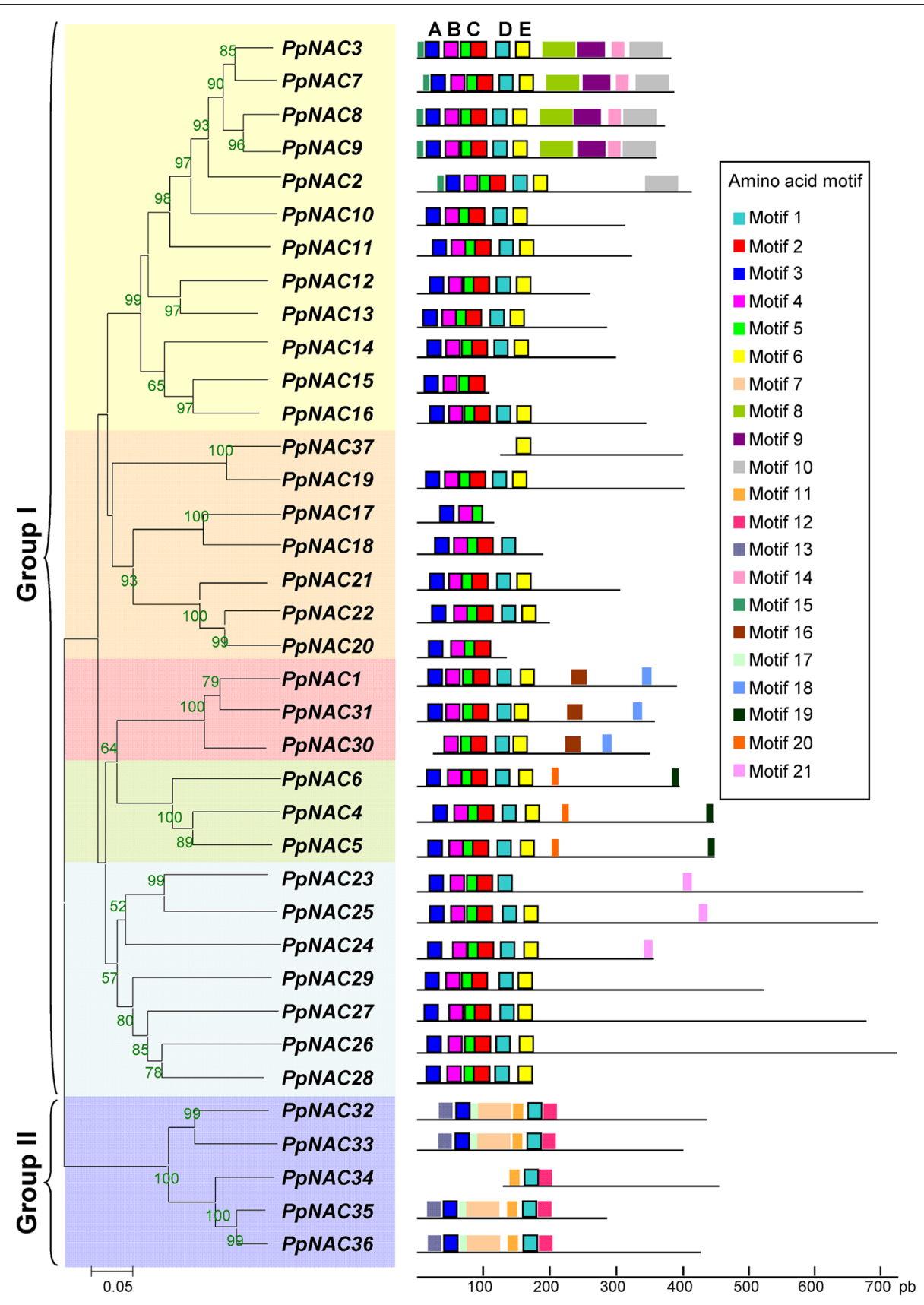

Fig. 1 The NAC protein family in P. pinaster. Multiple alignments of the 37 proteins encoded by NAC genes from $P$. pinaster were executed by Clustal $X$, and the phylogenetic tree was constructed using MEGA 4.0 via the Neighbor-Joining (NJ) method with 1000 bootstrap replicates. Percentage bootstrap score higher than $50 \%$ and subfamily classification are indicated. Amino acid motifs in the NAC proteins (1 to 21) are represented by colored boxes (Additional file 2). The black lines indicate relative protein lengths

the MEME program [45]. Twenty-one protein motifs containing 6 to 50 residues were identified. To simplify, we considered only those motifs that are present in more than half of the members of a cluster. Most of the closely related members in the phylogenetic tree had common motif compositions (Fig. 1). Five subdomains, A-E, were previously defined in the N-terminal region of NAC proteins $[20,46]$. We assigned Motif 3 to subdomain A, Motif
4 to subdomain B, Motif 5 and Motif 2 to subdomain C, Motif 1 to subdomain D and Motif 6 to subdomain E (Fig. 1 and Additional file 2). The subdomain distribution on the N-terminal region of on different NAC proteins is showed in the Additional file 3. Most of the maritime pine NAC proteins contain subdomains $A$ to $E$ in the DNAbinding domain; however members of Group II only contain subdomains A and D and lack subdomains B, C 
and E. These proteins contain the Motif 7 in the $\mathrm{N}$ terminal region, which seems to have replaced Motifs 2, 4 and 5 from most PpNAC sequences. Group II proteins also contain Motifs 11, 12 and 13 in the NAC domain. The Cterminal region is highly divergent, although we were able to identify certain specific motifs present in NAC proteins from specific clusters of Group I (Additional file 2). Motifs $8,9,10$ and 14 were present in the NAC proteins included in the largest cluster. The biological significance of most of the putative motifs is unknown and requires further investigation, but it is tempting to speculate that the structural homology may be related to function.

To explore the phylogenetic relationships of maritime pine NAC factors and other members of this family in plants the sequences obtained in this work and the fulllength protein sequences of $P$. glauca, P. abies, A. thaliana and Physcomitrella patens were compared. Figure 2 shows that the pine NAC family can be classified into six subfamilies (a-h) according to [46]. Group I comprises the
NAC-a, NAC-b, NAC-c, NAC-d and NAC-e subfamilies, whereas Group II comprises subfamily NAC-g. The clade NAC-a is the largest in P. pinaster including 12 sequences. This clade includes genes that are phylogenetically close to stress-related genes such as ATAF1 and ATAF2 [41] and PpaNAC09, PgNAC04 and PgNAC07 (Additional file 4) $[23,46]$.

The clade NAC-b includes seven $P$. pinaster sequences with similarity to proteins with transmembrane motifs in their C-terminals that mediate either cytokinin signalling during cell division or endoplasmatic reticulum stress responses [28, 47]. The NAC-e clade includes seven $P$. pinaster sequences and the FEZ gene, which has been demonstrated to be associated with the orientation of cell division in root stem cells [29]. Three $P$. pinaster sequences were grouped in the NAC-c clade with the NAC involved in vascular development, such as VND1/ 2, NST1/2, SND1 and SMB [48-50]. Three P. pinaster sequences are clustered in clade NAC-d together with

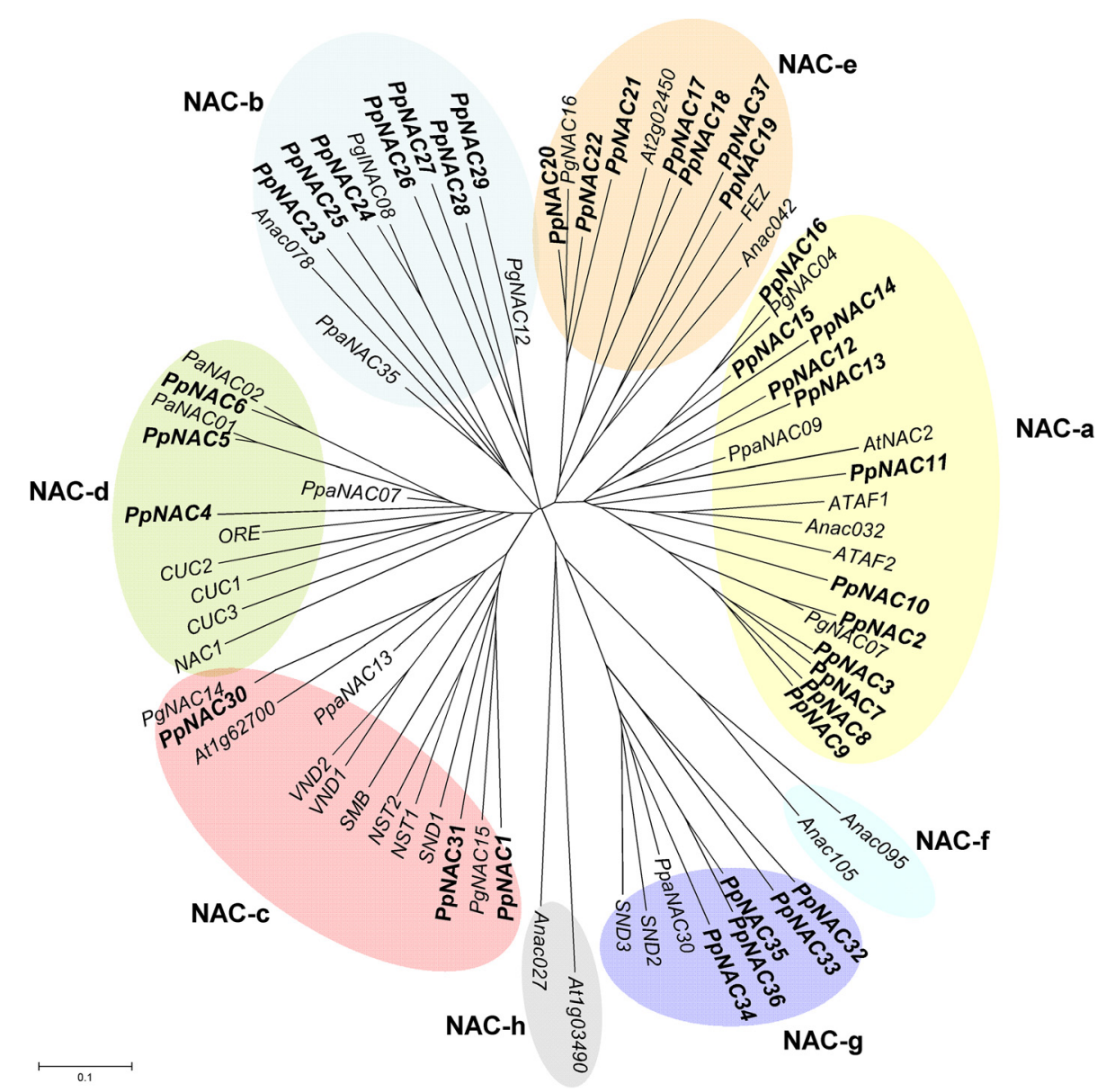

Fig. 2 Phylogenetic analysis of Arabidopsis thaliana, Physcomitrella patens, Picea abies, Picea glauca and Pinus pinaster NAC proteins. The phylogenetic tree was constructed with full-length NAC amino acid sequences using the Neighbor-Joining method. Major clades previously identified by [46] are indicated $(a-h)$. The accession numbers of sequences used in the analysis are available in Additional file 4: Table S2 
CUC1/2/3 and ORE genes from Arabidopsis [51-54], and PaNAC1 and PaNAC2 genes from P. abies [23]; the genes of this clade may be involved in organ initiation and differentiation. Five sequences clustered with clade NAC-g together with the SND2 and SND3 genes of Arabidopsis; these genes are involved in the secondary cell wall transcriptional network [55]. Clades NAC-f and NAC-h did not harbor any $P$. pinaster NAC genes. The functions of most NAC genes that clustered with these two clades still remain unknown, but it is significant that there is no representative of these sub-families in maritime pine.

\section{Cloning and molecular characterization of two NAC genes in $P$. pinaster}

Based on previous microarray data obtained in our laboratory, two maritime pine $N A C$ genes in the NAC-a subfamily, $P p N A C 2$ and $P p N A C 3$ (Fig. 2), were selectedfor functional characterization. $P p N A C 2$ and $P p N A C 3$ cDNA were cloned using PCR and fully sequenced. These genes displayed $75 \%$ sequence identity to Arabidopsis ATAF1 and ATAF2, which are reported to be NAC transcription factors with biological functions in abiotic and biotic stress responses $[40,41]$. The cDNA for $P p N A C 2$ was $1170 \mathrm{bp}$ in length and contained an ORF encoding a protein of 387 amino acids whereas the PpNAC3 cDNA was 1152 bp in length with a deduced amino acid sequence of 383 amino acids. Regulatory sequences upstream of the initiation codon of PpNAC2 (of $661 \mathrm{bp})$ and PpNAC3 (1115 bp) were isolated using a Genome Walking approach.

\section{$P p N A C 2$ and $P p N A C 3$ spatial and temporal organ-specific expression}

To determine the spatial and developmental expression patterns of these genes in $P$. pinaster, total RNA was extracted from various plant organs, and their relative abundance was analyzed by quantitative PCR (qPCR). Gene expression of $P p N A C 2$ and $P p N A C 3$ was analyzed in seedlings bearing cotyledons $0.5,1.0$ and $2.0 \mathrm{~cm}$ in length and in 2-month-old plantlets (Fig. 3a). In the seedlings, $P p N A C 2$ transcripts were particularly abundant in the cotyledons and hypocotyls, while much lower levels were found in roots. In contrast, $P p N A C 3$ was predominantly expressed in the roots of the seedlings during development. Interestingly, $P p N A C 2$ and $P p N A C 3$ exhibited a similar tissue-specific pattern of expression in 2-monthold plantlets with maximum levels of transcripts detected in the needles (Fig. 3b). Notably, the expression level of $P p N A C 2$ was an order of magnitude higher than of PpNAC3. The transcript levels were normalized to the expression levels of reference genes, as described in the Methods section.

\section{PpNAC2 and PpNAC3 expression in response to abiotic stresses and hormone treatments}

To test whether PpNAC2 and PpNAC3 are stressresponsive genes, we performed a qPCR analysis on total RNA isolated from the cotyledons, hypocotyls and roots of seedlings subjected to different stresses. The expression $P p N A C 2$ and $P p N A C 3$ was upregulated in response to MeJA and wounding (Fig. 4, MeJA, Wounding). However, $P p N A C 2$ exhibited a sustained response in hypocotyls and roots during a period of $24 \mathrm{~h}$ whereas a short-term response was observed for PpNAC3 at $2 \mathrm{~h}$, preferentially in hypocotyls. The response to ABA was only detected $24 \mathrm{~h}$ after treatment, and it was observed exclusively in roots for PpNAC2 and in cotyledons for PpNAC3 (Fig. 4, ABA). In contrast, $P p N A C 2$ and $P p N A C 3$ responded similarly to $\mathrm{NaCl}$ and cold treatments (Fig. 4, NaCl, Cold). It is worth mentioning that the magnitude of the response to the different treatments was always higher for PpNAC3 than for $P p N A C 2$. Specifically, the observed induction of $P p N A C 3$ was aproximately 10 -fold that of $P p N A C 2$ in response to MeJA, wounding and cold.

\section{PpNAC2 and PpNAC3 promoters contain cis-elements involved in biotic and abiotic stress}

To further explore the regulation of these $N A C$ genes in maritime pine the $5^{\prime}$-upstream sequences of $P p N A C 2$ and $P p N A C 3$ were subjected to a search in the PLACE database (https://sogo.dna.affrc.go.jp/cgi-bin/sogo.cgi) [56] to identify putative cis-regulatory elements. The analysis showed that both promoters had similar stress responsive cis-elements such as DPBF1 (ABA-responsive element), W-boxes, GCC-boxes, MYB binding sites and Wboxes (Fig. 5). This analysis also revealed that 3 E-boxes (CANNTG) are located in the $661 \mathrm{nt}$ of $P p N A C 2$ promoter sequence, and 6 E-boxes are located in the 1,115 nt of $P p N A C 3$ promoter sequence. E-boxes have been found in the promoters of defense genes in plants [57]. Furthermore, E-boxes are well-characterized binding sites for bHLH TFs in plants and are considered the cognate element for AtMYC2 binding, which has an important role in the activation of early jasmonate-responsive genes in Arabidopsis [58, 59]. These elements are commonly found in the promoters of genes that respond to MeJA [59, 60].

\section{Functional analysis of the PpNAC3 promoter in N. benthamiana}

Because the production of stably expressing conifer lines takes about one year and the selection of transgenic lines is a laborious process, we performed transient expression assays in Nicotiana as a simple and efficient method for the quantitative analysis of plant promoters in vivo [61, 62]. The promoter of PpNAC3 was selected for functional analysis based on its observed response to stress (Fig. 4). 


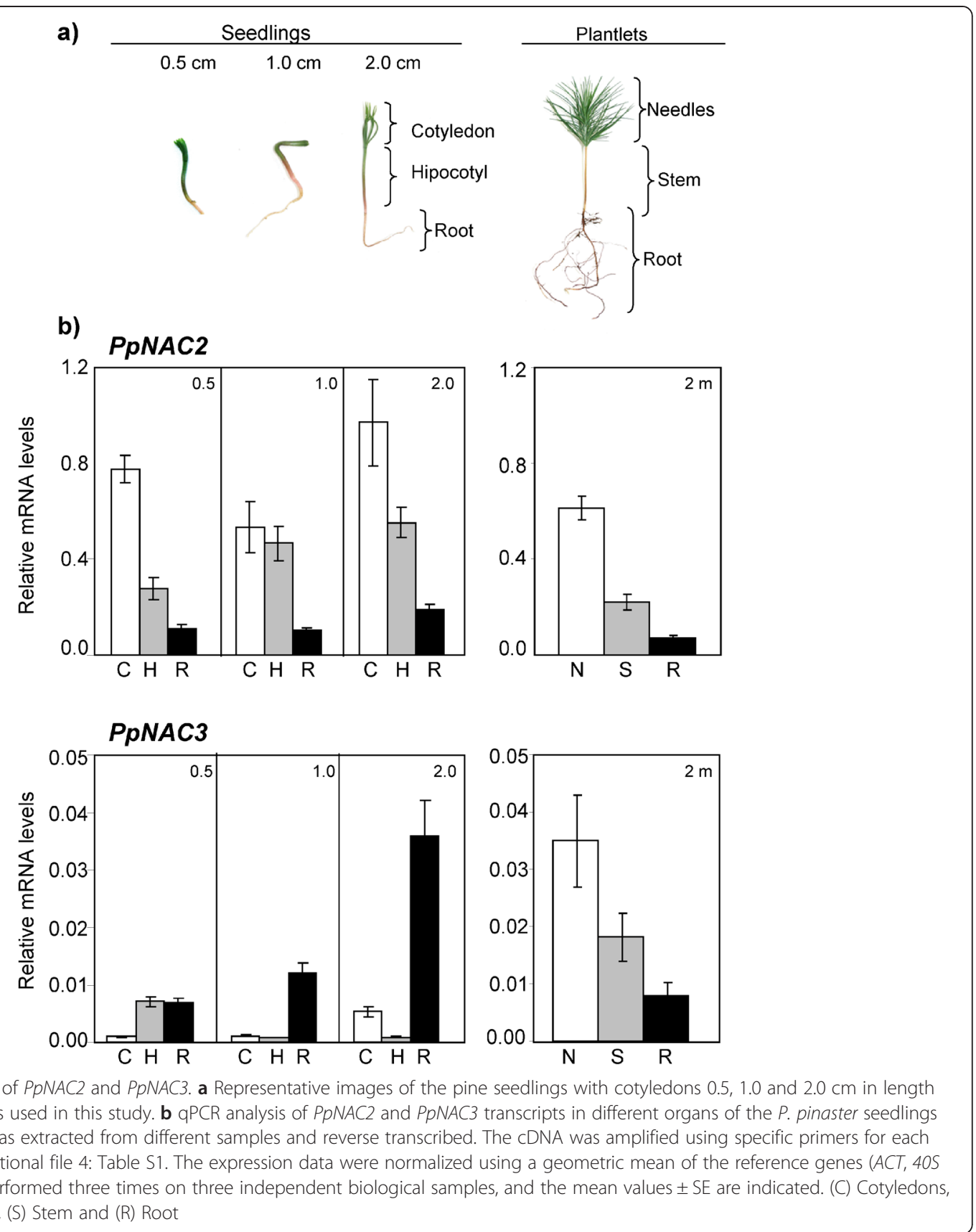

A construct containing the promoter region of $P p N A C 3$ (1115 bp) was fused to the GFP reporter gene in the binary vector $\mathrm{p} 35 \mathrm{~S}-\mathrm{GFP}$, replacing the $35 \mathrm{~S}$ promoter and generating $\mathrm{P}_{\mathrm{NAC} 3}-\mathrm{GFP}$. p35S-GFP was used as the positive control, and MES buffer and p35S-GFP without the 35S promoter (p0-GFP) were used as the negative controls (Fig. 6a). N. benthamiana leaves were agroinfiltrated with Agrobacterium containing the various constructs (Fig. 6b). MeJA activated the transcription of the reported gene driven by the PpNAC3 promoter (Fig. 6c, $\mathrm{P}_{\mathrm{NAC} 3}-\mathrm{GFP}$ ). In comparison with water-treated leaves, an approximately 3-fold increase in GFP expression was observed after 2, 8 and $24 \mathrm{~h}$ of the MeJA treatment. In contrast, leaves infiltrated with the negative control or with MES buffer showed no increase in GFP expression (Fig. 6c, P0-GFP). The leaves infiltrated with the positive control exhibited a transient increase in GFP expression regardless of whether they were treated with MeJA or water (Fig. 6c, P35SGFP). As an additional control, the expression level of the endogenous PR4 gene was analyzed as a marker for the jasmonic acid-dependent signalling pathway. As shown in Fig. 6c (PR4), the expression of PR4 was rapidly induced 


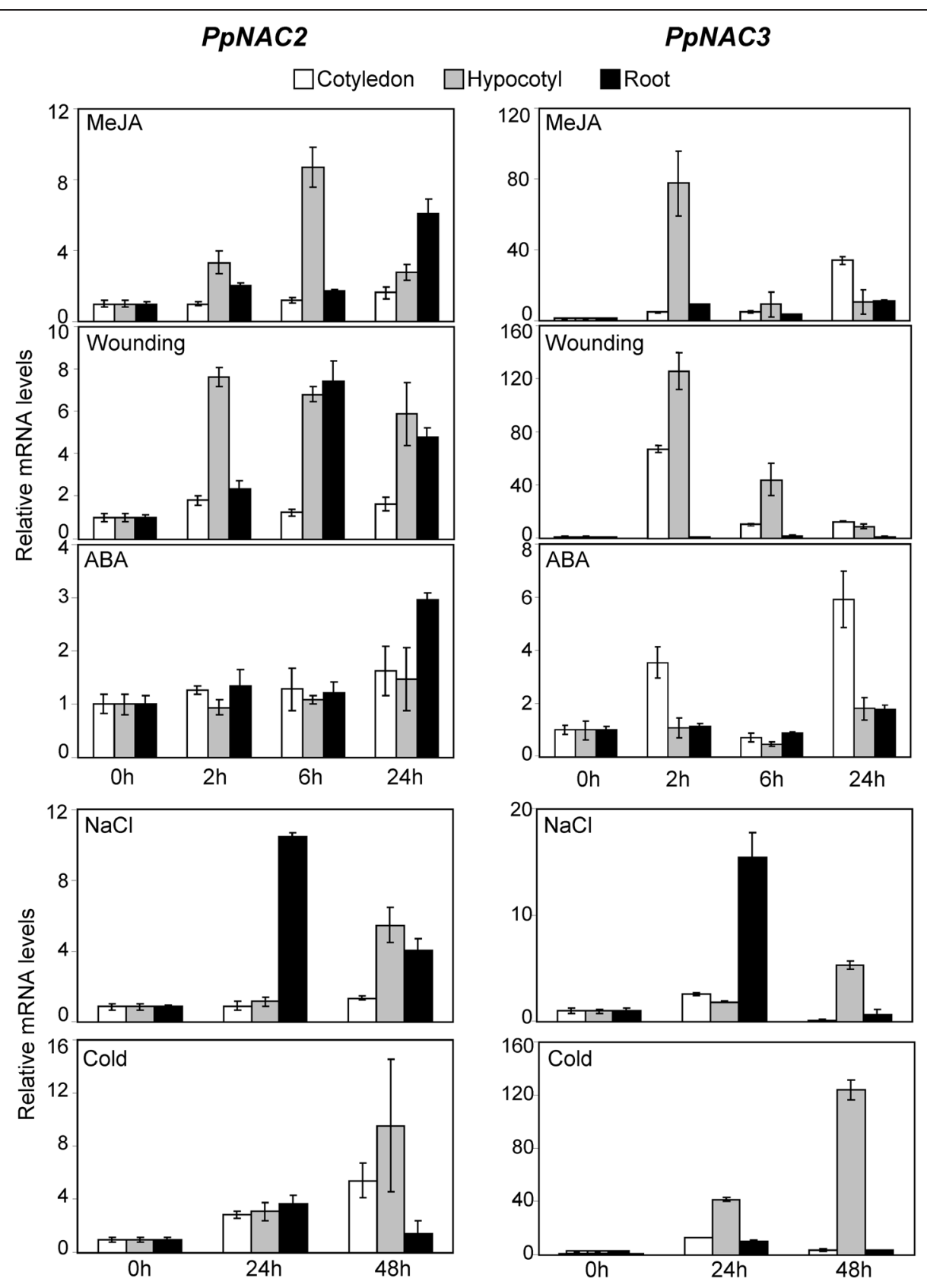

Fig. 4 Stress-responsive transcript profiles of PpNAC2 and PpNAC3 as determined by qPCR. Transcript accumulation in cotyledons, hypocotyls and roots from 3-week-old seedlings in response to $100 \mu \mathrm{M}$ MeJA, mechanical wounding and $50 \mu \mathrm{M}$ ABA (after 0, 2, 8 and 24 h); in response to $250 \mathrm{mM} \mathrm{NaCl}$ (after 0,24 and $48 \mathrm{~h}$ ) and exposure to cold (after 0,24 and $48 \mathrm{~h}$ ). Data were normalized using a geometric mean of the reference genes (ACT, $40 S$ and EFIa). Mean values \pm SE are shown for three independent experiments

by MeJA, and the observed profile was quite similar to that mediated by the PpNAC3 promoter.

\section{Regulation of expression mediated by the PpNAC3} promoter in $\mathrm{NbbHLH2}$ silenced plants

To further investigate the jasmonate-mediated regulation of the PpNAC3 promoter in N. benthamiana we used a VIGS approach to silence bHLH MYC proteins.
Previous reports have shown that promoter sequences that are recognized and bound by MYC2 proteins are highly conserved between different groups of plants $[58,63]$. In $N$. benthamiana, the proteins $N b b H L H 1$ and NbbHLH2 can bind an E-box element in the PMT promoter [64] and activate it [65].

Using RT-PCR and specific primers, we obtained a $400 \mathrm{bp}$ fragment corresponding to the 5 'region of the 


\begin{tabular}{|c|c|c|c|}
\hline \multirow[b]{2}{*}{ PpNAC2 } & & $800 \mathrm{pb}$ & $400 \mathrm{pb}$ \\
\hline & \multicolumn{3}{|r|}{$0.661 \mathrm{~kb}$} \\
\hline \multirow[t]{9}{*}{ PpNAC3 } & $1.115 \mathrm{~kb}$ & $H+\nabla+0$ & 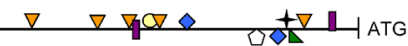 \\
\hline & Symbol & Cis-element & Function \\
\hline & $\Delta$ & DPBF1 & ABA response \\
\hline & 0 & DRE & Enviromental stress \\
\hline & t & E-box & MYC consensus \\
\hline & 0 & GCC box & Ehylene responsive element \\
\hline & प & LTRE & Stress response \\
\hline & $\nabla$ & MYB & Enviromental stress \\
\hline & $\diamond$ & W-box & Plant defense response \\
\hline \multicolumn{4}{|c|}{$\begin{array}{l}\text { Fig. } 5 \text { Distribution scheme of putative cis-acting elements in the } \\
\text { PpNAC2 and PpNAC3 gene promoters. The 5'regulatory region of } \\
\text { these genes was analyzed for the presence of putative cis-acting } \\
\text { regulatory elements using the plant cis-acting regulatory DNA } \\
\text { elements (PLACE) database (http://www.dna.affrc.go.jp/PLACE/, and } \\
\text { some stress-responsive and hormonal regulation cis-elements listed } \\
\text { in the PLACE database were mapped. The relative positions are } \\
\text { presented with respect to the first base of the translation start site } \\
\text { (ATG) }\end{array}$} \\
\hline
\end{tabular}

open reading frame of the NbbHLH2 gene. The fragment was inserted into the vector pTRVGW (pTRVNbbHLH2), a Gateway-compatible tobacco rattle virus vector [66]. Four weeks later, NbbHLH2-silenced plants showed no change in morphology compared to PTRV control plants (Fig. 7a). Silencing of the endogenous phytoene desaturase gene, NbPDS, was used as a control for the effectiveness of VIGS. The degree of silencing was assessed by qPCR, demonstrating that NbbHLH2 transcript abundance was reduced by approximately $85 \%$ compared to that of pTRV control plants (Fig. 7b).

The MeJA regulation of the PpNAC3 promoter was studied in $N$. benthamiana leaves after silencing $\mathrm{NbbHLH2}$. After $48 \mathrm{~h}$ of agroinfiltration with the $\mathrm{P}_{\mathrm{NAC} 3}$-GFP construct, the leaves were treated with MeJA, and GFP expression was determined at 0,2 and $4 \mathrm{~h}$. As shown in Fig. 7c, in $N$. benthamiana leaves with silencing of the endogenous NbbHLH2 gene, the level of the GFP transcripts were not altered after MeJA treatment.

\section{Discussion}

Forest trees are routinely exposed to environmental stresses. Current and predicted climatic conditions, such as prolonged drought, increased salinization of soil and water, and high-temperature episodes, are a serious threat to forest productivity worldwide, affecting tree growth and survival. An understanding of how forest trees adapt to hostile environmental conditions is necessary to sustain productivity and to meet future demand for forest-derived products. Current efforts to use molecular analyses and genetic engineering to improve abiotic stress tolerance depend on a thorough understanding of plant signaling pathways involved in the response to stress, as well as on the identification of key regulatory proteins [67].

In this work, we have identified 37 non-redundant NAC domain proteins in the $P$. pinaster genome. This number is close to those previously reported for Picea glauca (36) [11, 44] and Physcomitrella patens ssp. patens (35) [68] but is substantially smaller than the reported number in angiosperm species: 117 in Arabidopsis, 151 in rice, 163 in poplar, 189 in eucalyptus and 152 each in soybean and tobacco [69-74]. Similar findings have also been reported for members of other TF gene families in conifers, such as the Dof gene family, which contains ten members in maritime and loblolly pines [75], noticeably fewer than the numbers of Dof genes in angiosperms $[76,77]$. These data suggest that the NAC gene family, as has occurred in other TF families, has expanded and diversified in angiosperms by gene duplication, creating paralogous genes with a high degree of sequence similarity and functional redundancy.

The $P$. pinaster NAC proteins can be phylogenetically clustered into two subgroups based on the similarities of their DNA-binding domains. The Group I has 31 members and can be further classified into five subgroups, and Group II consists of six NAC proteins (Fig. 1). The conserved motif identified using the MEME program defines six subfamilies of $P$. pinaster NAC proteins, which was consistent with our phylogenetic analysis. Furthermore, of the five subdomains (A-E) identified in the N-terminal region of all proteins in Group I, we identified four conserved motifs (Motifs 7, 11, 12 and 13), which were also located in the $\mathrm{N}$-terminal regions of Group II NAC proteins. Specifically Motif 7 is similar to Motif 9, which has been found in a minority of NAC proteins of various plants [74]. This motif is homologous to the NAM domain (PF02365) and appears to replace Motifs 2, 4 and 5 (Fig. 1b). Most of the conserved motifs located in the C-terminal regions are novel, but some of them have been found to be related despite performing different functions. For example, Motif 10 has been previously described as a transcriptional activation motif $[20,78]$, and it is present in stress-related genes. Motifs 19 and 20, conserved among the members of one subfamily, correspond to the W-motif and L-motif, respectively, as previously described for the C-terminal domain of the CUC subfamily [23, 52, 79]. However, the biological significance of most of the protein motifs is currently unknown and therefore remains to be further investigated.

Shen et al. (2009) carried out a genome-wide bioinformatics survey on plant NAC domain TFs from different 


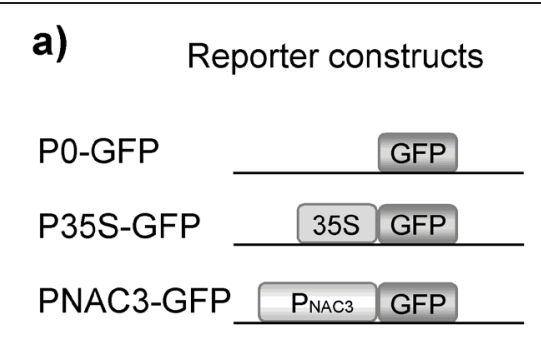

b)

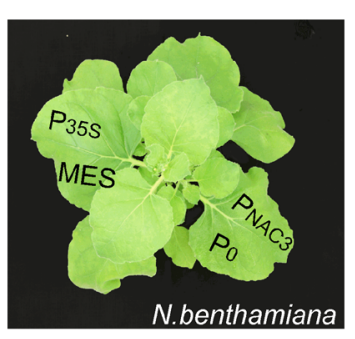

c)

$\square \mathrm{sdw} \quad \square 100 \mu \mathrm{M} \mathrm{MeJA}$
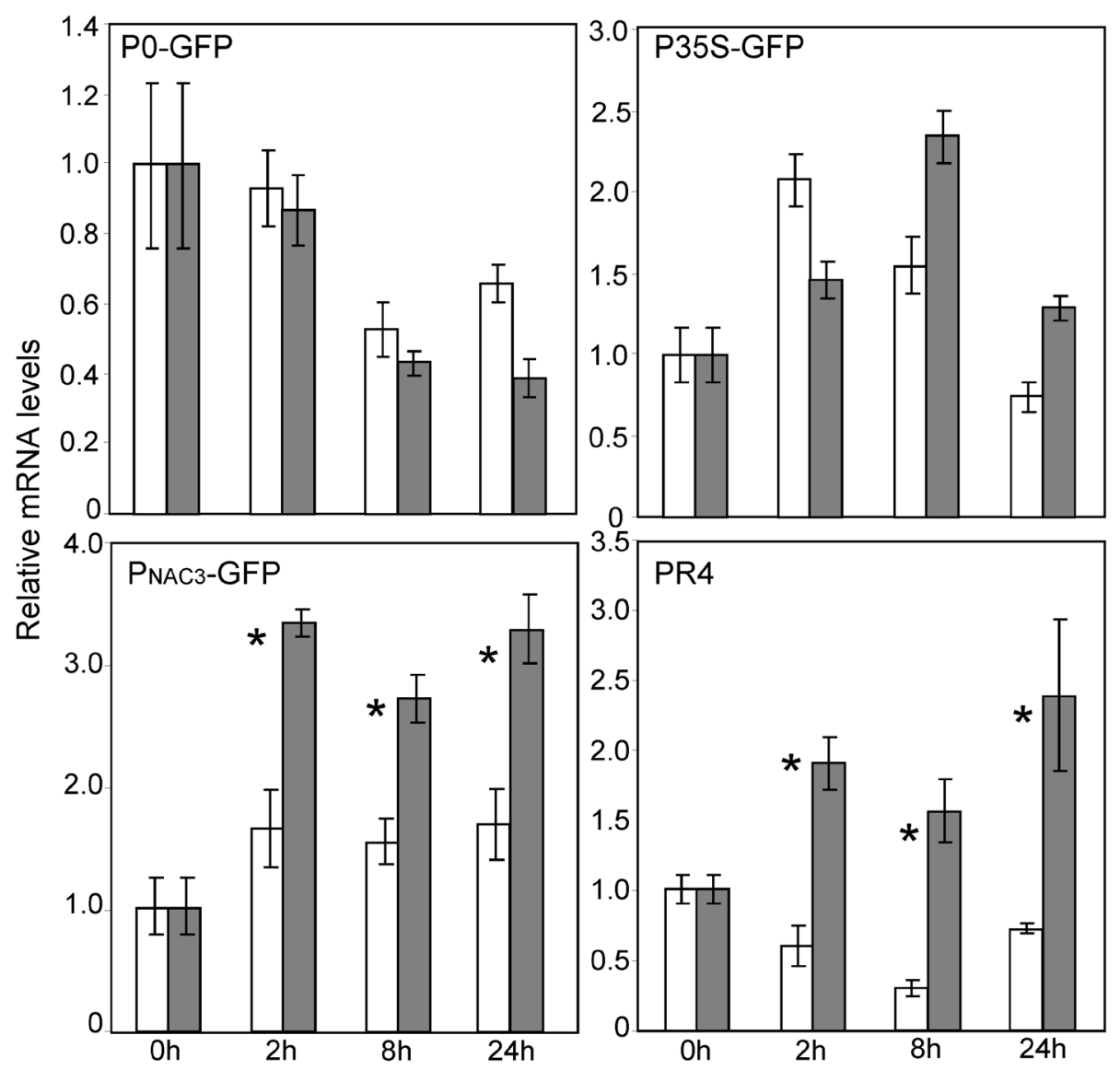

Fig. 6 Transient expression of the PpNAC3 promoter fused to GFP in N. benthamiana leaves. a Diagram of constructs used for the Agrobacteriummediated transient expression assay in $N$. benthamiana leaves. $\mathbf{b}$ Plants of $\mathrm{N}$. benthamiana used for agroinfiltration. The constructs were agroinfiltrated as shown in the image. We used different leaves of the same plant for each construct, and the experiment was performed in triplicate. After $48 \mathrm{~h}$, the leaves were treated with $100 \mu \mathrm{M}$ MeJA or with water as a control. c Total RNA was isolated from N. benthamiana leaves and GFP or PR4 expression was studied at 2, 8 and $24 \mathrm{~h}$ after MeJA or water treatment using qPCR. Data were normalized to NbActin as a reference gene. Expression levels are relative to the values at time zero. The mean values \pm SE are indicated. Asterisks indicate significant differences between the two treatments

plant species, without including any gymnosperms in the analysis. The phylogenetic analyses of $P$. pinaster NAC proteins together with the characterized NAC proteins from other plants suggest that all NAC sequences from $P$. pinaster could be included in the different clades (Fig. 2a), as previously indicated by [46]. However, clades $\mathrm{f}$ and $\mathrm{h}$ did not harbor any $P$. pinaster NAC proteins. Interestingly, the NAC-f subfamily was also absent in mosses (P. patens, bryophyte), spike moss (S. moellendorffii, lycophyte) and white spruce (P. glauca), suggesting that this clade emerged later than the other six clades and presumably has distinct and possibly more specific and specialized functions $[23,46]$.

The high sequence diversification of the NAC family, especially the $\mathrm{C}$-terminal domain, suggests that the function of this family has also been diversified. 
a)

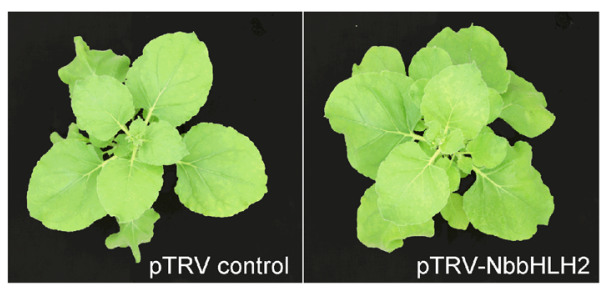

c)

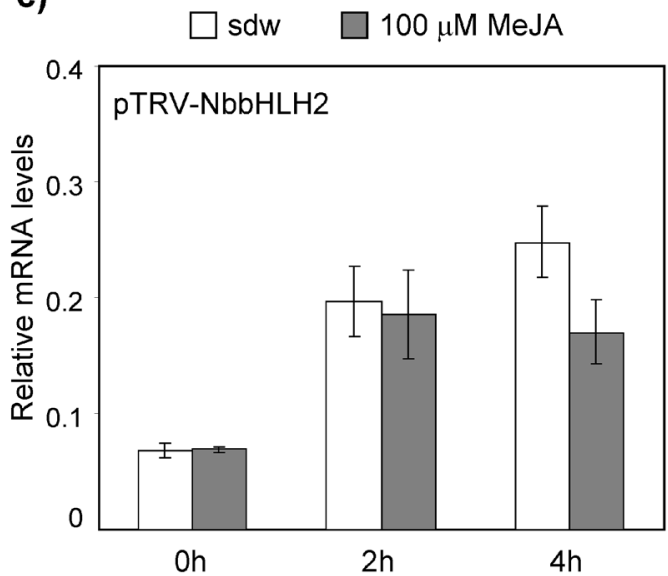

b)

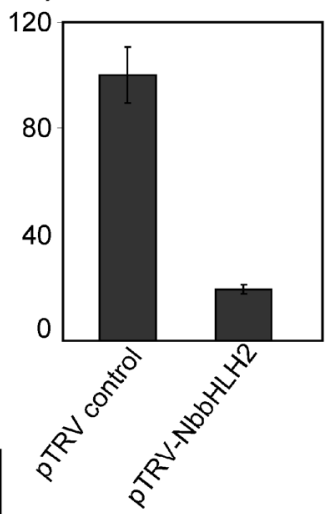

Fig. 7 Functional analysis of the PpNAC3 promoter in VIGS-silenced NbbHLH2 plants. a Photographs of 6-week-old control (pTRV-control) and NbbHLH2-silenced plants. b The relative expression level of NbbHLH2 was determined by qPCR in pTRV control and $\mathrm{N}$. benthamiana plants with NbbHLH2 suppression. c GFP expression driven by the PpNAC3 promoter in pTRV-NbbHLH2-silenced plants. After 48 h of agroinfiltration with the $\mathrm{P}_{\mathrm{NAC} 3}-\mathrm{GFP}$ construct, the leaves were treated with either $100 \mu \mathrm{M}$ MeJA or with water as a control. NbActin was used as the endogenous qPCR control. The error bars represent the SD from three biological replicates measured in triplicate

This is supported by previous reports on NAC proteins involved in various aspects of plant growth, development and stress responses.

The NAC-encoding genes that are evolutionarily closely related often exert similar functions $[46,80]$. In the phylogenetic analysis performed in maritime pine, PpNAC2 and PpNAC3 clustered within the clade NAC-a, suggesting that these TFs may play similar roles to the Arabidopsis drought-inducible ATAF1 and ATAF2 [40, 41].

Expression of PpNAC2 and PpNAC3 was detected in all tissues tested by qPCR, with higher expression levels of PpNAC2 in cotyledons and hypocotyls of seedlings, while gene expression levels of $P p N A C 3$ were particularly abundant in seedling roots (Fig. 3b). This expression pattern suggests that the two genes may perform non-redundant functions in pine seedlings. The closest homologues in Arabidopsis, ATAF1 and ATAF2, were also expressed in all tissues; however, according to data derived from Genevestigator, ATAF1 showed higher expression levels in roots, while ATAF2 was detected at a higher level in cotyledons and leaves. This transcript distribution pattern in Arabidopsis is quite similar to the observed expression pattern of $P p N A C 3$ and $P p N A C 2$ in pine. Different reports in the literature have shown that NAC transcription factors play important roles in plant growth, development, hormone signaling and the plant stress response. ATAF1 acts as a negative regulator of ABA signaling but induces JA/ ET-associated defense signaling marker genes [31]. However, ATAF2 is induced by dehydration as well as by JA and SA [40]. ANAC19, ANAC055 and RD26 (ANAC072) are induced by drought, high salinity and/or abscisic acid, and the overexpression of these genes up-regulates the expression of several stress-related genes, resulting in the enhancement of plant tolerance to drought stress [38]. Similarly, our study indicates that PpNAC2 and PpNAC3 are induced by multiple stress treatments, including salinity, cold and mechanical wounding (Fig. 4). These results suggested that PpNAC2 and PpNAC3 may be involved in the general response of $P$. pinaster to abiotic stress. Interestingly, both genes were strongly induced by wounding and MeJA treatments in the seedlings. The role of MeJA as a transportable intercellular molecule that can move from leaves to roots or to other tissues has been established in Arabidopsis and in plants of the Solanaceae family [81, 82]. This may explain the rapid response of $P p N A C 2$ and PpNAC3 genes in hypocotyls following the 
application of MeJA to the cotyledons. The very rapid accumulation of $P p N A C 3$ transcripts observed two hours after treatment also suggests that $P p N A C 3$ is particularly involved in short-term responses to stress. The genes StNAC in potato, OsNAC6 in rice, and ATAF1 and ATAF2 in Arabidopsis, all with high levels of homology to $P p N A C 2$ and $P p N A C 3$, are upregulated by the wounding/ pathogenesis-related phytohormone MeJA [40, 83, 84]. Many NAC transcription factors respond to multiple stress signals, and their protein products may participate in the regulation of several apparently unrelated processes as either negative or positive regulators [85].

The analysis of the promoter regions of PpNAC2 and $P p N A C 3$ was a pre-requisite to further understand the regulatory control of the stress-inducible expression of these two genes (Fig. 5). Both promoters had several previously characterized stress-responsive cis-elements, including DPBF1 (ABA-responsive element) and MYB binding sites [86-88]. Other elements known to be responsive to environmental stimuli, such as light, pathogens, dehydration and low temperature (specifically, W-boxes [89] and GCC-boxes [90]) were also present. $\mathrm{W}$-boxes and GCC-boxes are known as recognition sites for WRKY and ERF transcription factors, respectively. The rapid and transient accumulation of $P p N A C 2$ and $P p N A C 3$ indicates their potential as early regulators in the response to wounding/MeJA. The in silico analysis of a putative cis-element in the $P p N A C 2$ and $P p N A C 3$ promoters also showed three E-boxes in $P p N A C 2$ and six E-boxes in PpNAC3 (Fig. 5). The E-box elements are commonly found on the promoters of genes that respond to MeJA, and they are well-characterized binding sites for bHLH transcription factors in plants. In general, the genes containing predicted stress-responsive cis-elements are actually induced by the corresponding stresses and we were particularly interested in the functional analysis of the transcriptional response of $P p N A C 3$ to MeJA. The functional analysis of conifer genes has been studied in other model plant species because of the long regeneration times and the technical complexity of producing transgenic trees [91, 92]. In this work, we studied the transcriptional regulation of the $P p N A C 3$ promoter using Agrobacterium-mediated transient expression in $N$. benthamiana leaves. This is a simple and efficient method for the quantitative analysis of plant promoters in vivo [61, 62]. Our results suggest that the E-boxes contained in the PpNAC3 proximal promoter region were transactivated by MeJA treatment in $N$. benthamiana leaves (Fig. 6c). This response disappeared when the $N$. benthamiana plants were silenced for the endogenous $\mathrm{NbbHLH2}$ gene (Fig. 7c). These results suggest that jasmonic acid induction of the PpNAC3 promoter is mediated by NbbHLH2 proteins. The PpNAC3 promoter fragment used in this study appears to contain most elements for proper PpNAC3 expression, and furthermore, these elements are also recognized in $N$. benthamiana despite the phylogenetic and evolutionary differences between these species.

Notably, although PpNAC3 is a gene with low expression in pine seedlings, its expression is rapidly and strongly increased in response to MeJA and to several stresses. This raises the possibility of using the PpNAC3 promoter as a potential MeJA-inducible heterologous promoter, for use as a biotechnological tool to drive gene expression in conifers and other plant species.

\section{Methods}

\section{Plant material and growth conditions}

Pinus pinaster Ait. seeds were provided by the Centro de Recursos Genéticos Forestales "El Serranillo" (Ministerio de Medio Ambiente y Medio Rural y Marino, Spain). Seeds were imbibed in distilled water for $24 \mathrm{~h}$ under continuous aeration and germinated and grown with vermiculite as a substrate under a growth regime of $16 \mathrm{~h}$ light/ $8 \mathrm{~h}$ dark at $23 \pm 1{ }^{\circ} \mathrm{C}$. Cotyledons, hypocotyls and root samples of pine seedlings were collected separately, frozen in liquid nitrogen and stored at $-80{ }^{\circ} \mathrm{C}$ until use.

Nicotiana benthamiana $L$. seeds were sown and grown in pots and maintained under a $16 \mathrm{~h}$ light $/ 8 \mathrm{~h}$ dark photoperiod at $24{ }^{\circ} \mathrm{C}$ for 6 weeks.

\section{Stresses treatments}

Four-weeks-old plantlets were used to conduct the stress treatments. Mechanical wounding was conducted by puncturing the hypocotyl with forceps and cutting onethird of the cotyledons. ABA $(50 \mu \mathrm{M})$ and MeJA $(100 \mu \mathrm{M})$ solutions were sprayed onto the aerial portion; controls were sprayed only with water [93, 94]. Cotyledons, hypocotyls and roots were harvested for analysis after $0 \mathrm{~h}, 2 \mathrm{~h}$, $8 \mathrm{~h}$ and $24 \mathrm{~h}$ of treatment. For $\mathrm{NaCl}$ stress, the plantlets were grown in vermiculite and irrigated with a water solution containing $250 \mathrm{mM} \mathrm{NaCl}$; controls were irrigated with water. For the low-temperature $\left(8{ }^{\circ} \mathrm{C}\right)$ treatment, seedlings grown in a chamber at $24{ }^{\circ} \mathrm{C}$ were transferred for $48 \mathrm{~h}$ at $8{ }^{\circ} \mathrm{C}$, while the control plants were kept at $24{ }^{\circ} \mathrm{C}$. NaCl-treated and cold-treated plants were harvested for analysis at $0 \mathrm{~h}, 24 \mathrm{~h}$ and $48 \mathrm{~h}$ after treatment. Three biological replicates for each treatment were collected. Tissue samples were collected separately from the biological replicates, frozen in liquid nitrogen and stored at $-80^{\circ} \mathrm{C}$ until analysis.

\section{Cloning of PpNAC2 and PpNAC3}

Full-length $P p N A C 2$ and $P p N A C 3$ cDNAs were cloned from pine seedling hypocotyl RNAs by reverse transcription-PCR (RT-PCR) using primers designed from $P$. pinaster sequences (SustainpineDB). Pine genomic DNA was isolated using the CTAB method [95] and the 
promoter sequences of both genes were amplified using the GenomeWalker ${ }^{\text {ri }}$ Universal kit (Clontech Laboratories, Mountain View, CA, USA). A 661-bp region of the PpNAC2 promoter and a 1115-bp region of the PpNAC3 promoter were isolated using the Advantage Genomic Polymerase mix (Clontech Laboratories, Mountain View, CA, USA). All the primers are listed in Additional file 5: Table S1. The cDNA and genomic sequences were inserted into the pGEM-3Zf $(+)$ cloning vector and sequenced on both strands using CEQ 8000 Genetic Analysis System (Beckman Coulter, Madrid, Spain).

\section{Plasmids construction for PpNAC3 Promoter analysis}

The pBI121 vector was modified by replacing the GUS reporter gene with a functional GFP gene, thereby placing the GFP gene under the control of the CaMV 35S promoter (p35S-GFP). A 1,165 bp genomic fragment upstream of the ATG $(+1)$ of the PpNAC3 gene was cloned into the pGEM-3Zf $(+)$. It was amplified using PCR with specific flanking primers containing restriction sites (Additional file 4: Table S1). After digestion, the product was inserted upstream the GFP gene in the binary vector $\mathrm{p} 35 \mathrm{~S}-\mathrm{GFP}$ replacing the $35 \mathrm{~S}$ promoter ( $\left.\mathrm{P}_{\mathrm{NAC} 3}-\mathrm{GFP}\right)$. The recombinant plasmid was introduced into Agrobacterium tumefaciens $\mathrm{C} 58 \mathrm{C} 1$ and the overnight cell cultures were centrifuged and resuspended in infiltration media containing $10 \mathrm{mM}$ MES- $\mathrm{KOH}$ (pH5.6) and $0.15 \mathrm{mM}$ acetosyringone. The optical density at $600 \mathrm{~nm}$ was adjusted to 0.5 before infiltration of the leaves of 4-5-week-old $N$. benthamiana plants. The p35SGPF plasmid was used as a positive control, and plasmid without the 35S promoter (P0-GFP) or MES were used as the negative controls. At $48 \mathrm{~h}$ after infiltration, $N$. benthamiana leaves were treated with $100 \mu \mathrm{M}$ MeJA solution or with water as a control. Three leaf discs $(10 \mathrm{~mm})$ of three independents plants were used for each time point tested. The experiments were repeated at least three times.

\section{Virus Induced Gene Silencing (VIGS) experiments}

A virus induced gene silencing (VIGS) system was used to transiently silence the transcription factor MYC2. We amplified a 400-bp fragment of the $N$. benthamiana bHLH2 (ADH04263.1) gene using specific Gateway adapter primers (Additional file 4: Table S1) recombined into pDONR207 (Invitrogen) and cloned into the VIGS Gateway-adapted destination vector pTRVGW. Constructs were verified by sequencing using a CEQ 8000 (Beckman Coulter, Spain). Subsequently, we transformed the A. tumefaciens strain $\mathrm{C} 58 \mathrm{C} 1$ with the empty plasmid (pTRV-control) or with a plasmid harbouring the insert (pTRV-NbbHLH2) and incubated the bacteria at $28{ }^{\circ} \mathrm{C}$ for two days. Silencing in $N$. benthamiana leaves was performed as described by [66]. Fifteen-day-old seedlings were infiltrated with cultures containing pTRV-control or pTRV-NbbHLH2 prepared in a 1:1 mix of each with the helper plasmid pTRV-1, both with an optical density at $600 \mathrm{~nm}$ of 0.1 . The plants were kept in the growth chamber under $16 \mathrm{~h}$ light/ $8 \mathrm{~h}$ dark regime at $24{ }^{\circ} \mathrm{C}$. We monitored the spread of silencing using control plants infiltrated with the pTRV-PDS construct which induced leaf bleaching, while the efficiency of silencing of the corresponding gene was determined by measuring transcript abundance by qPCR using specific primers (Additional file 4: Table S1). Four weeks after silencing, $N$. benthamiana plant leaves were agroinfiltrated with $\mathrm{P}_{\mathrm{NAC} 3}-\mathrm{GFP}, \mathrm{P} 35 \mathrm{~S}-$ GFP and P0-GFP constructs; after $48 \mathrm{~h}$ the leaves were treated either with $100 \mu \mathrm{M}$ MeJA solution or with water as a control. Three leaf discs $(10 \mathrm{~mm})$ of three independent plants were used for each time point tested. The experiments were repeated in triplicate, and results from a representative experiment are shown.

\section{RNA isolation and qPCR}

Total RNA was extracted following the protocol described previously [96]. RNA samples were treated with RQ1 RNase-Free DNase (Promega), and cDNA synthesis was performed with iScript Reverse Transcription Supermix (Bio-Rad) in the presence of oligo (dT) or random primers. Real-time PCR was performed in a reaction volume of $10 \mu \mathrm{l}$ containing cDNA (10 ng) and $5 \mu \mathrm{l}$ of SsoFast EvaGreen Supermix (Bio-Rad) using a CFX384 Real- Time System C1000 Thermal Cycler (Bio-Rad) with annealing at $60{ }^{\circ} \mathrm{C}$ for $10 \mathrm{~s}$ and extension at $72{ }^{\circ} \mathrm{C}$ for $15 \mathrm{~s}$. The reactions were run for 40 cycles, and after the final cycle, a melting curve was performed to verify the reaction specificity. Actin, elongation factor-1-alpha (EF1- $\alpha$ ), and 40S ribosomal protein were used as reference genes in pine, and actin was used as a reference gene in $N$. benthamiana samples. The fluorescence of the PCR products was continuously monitored using an iQ5 cycler (Bio-Rad), and relative gene expression was estimated as previously described [94]. The gene-specific primers used are described in Additional file 4: Table S1.

\section{Bioinformatics}

\section{Database search and phylogenetic analysis}

The program Clustal X, version 1.83, was used for multiple sequence alignments of the full-length protein sequences, including the highly conserved $\mathrm{N}$-terminal NAC domain and the more divergent C-terminal domain. The unrooted phylogenetic trees were constructed with MEGA 4.0 using the Neighbor-Joining (NJ) method, and the bootstrap test was carried out with 1000 iterations. A pairwise gap deletion mode was used to ensure that the more divergent $\mathrm{C}$-terminal domains could contribute to the topology of the NJ tree. 


\section{Motif identification}

Protein sequence motifs were identified using the MEME (Multiple Expectation Maximization for Motif Elicitation) program version 4.9.1 (http://meme.nbcr.net/meme/cgibin/meme.cgi, [45]), with the following parameters: number of repetitions, any; maximum number of motifs, 50; and optimum width of the motif between 6 and 50 residues. The motif profile for each protein is presented schematically.

\section{Identification of cis-regulatory elements}

For the in silico study of PpNAC2 and PpNAC3 promoter sequences and to determine the cis-acting regulatory elements a search using the plant databases PlantCARE (http://bioinformatics.psb.ugent.be/webtools/plantcare/ html/) and PLACE (http://www.dna.affrc.go.jp/PLACE/) was conducted.

\section{Conclusions}

In summary, we have studied the composition of the NAC transcription factors family in maritime pine and classified 37 NAC genes into six subfamilies. The largest group included 12 genes stress-related. We have characterized the expression profiles of two genes of this group: $P p N A C 2$ and $P p N A C 3$, in response to various types of stress. Both genes were strongly induced by methyl jasmonate, mechanical wounding and high salinity. In addition, the study in silico of both promoters revealed the existence of cis-elements such as E-boxes, which are commonly found in promoters that respond to jasmonate and are binding sites for bHLH proteins. Using a transient expression assay in $N$. benthamiana leaves we found that the promoter of PpNAC3 was rapidly induced upon MeJA treatment however, this response disappeared in plants in which the internal transcription factor NbbHLH2 had been silenced. Our results suggest that $P p N A C 2$ and $P p N A C 3$ encode stress-responsive NAC transcription factors involved in the jasmonate response in maritime pine. Furthermore, our results support the idea that NbbHLH2 proteins can mediate jasmonic acid induction of PpNAC3 promoter suggesting that the jasmonate signaling pathway could be conserved between angiosperms and gymnosperms. These findings raise the possibility of using PpNAC3 promoter as a biotechnological tool to drive MeJA-inducible expression in conifers and other plants.

\section{Additional files}

Additional file 1: Names, gene accession numbers and sequences of the $P$. pinaster NAC proteins. (XLS $37 \mathrm{~kb}$ )

Additional file 2: Amino acid sequence logos of 21 motifs identified in PpNAC proteins using MEME. Data shown are the number of proteins containing each motif, the width, the E-value, the domain in which it is located, and the annotation of each motif is indicated. (XLS $379 \mathrm{~kb}$ )

Additional file 3: Figure S1. Sequence alignment of PpNAC proteins from $P$. pinaster. Amino acid motifs (A-E) in the NAC proteins are represented by colored boxes. Secondary structure elements ( $\beta, a$, helices) of the NAC domain are indicated above the alignment. (TIFF $544 \mathrm{~kb}$ )

Additional file 4: Table S2. Gene accession numbers, names and references for the genes used in the phylogenetic analysis. Phylogenetic groups according to Shen et al. (2009) [46] and the groups generated in this study are indicated. (DOC $95 \mathrm{~kb}$ )

Additional file 5: Table S1. Oligonucleotides used in this work. (DOC $50 \mathrm{~kb}$ )

Competing interests

We confirm that none of the authors have any competing interests.

\section{Authors' contributions}

MBP and CA designed the experiments. MBP did the experimental work. $M B P, C A$ and FMC analyzed data and wrote the manuscript. All authors read and approved the final manuscript.

\section{Acknowledgments}

We thank Dr. Fernando de la Torre (Universidad de Málaga) for the TRVGW silencing vector and for technical advice regarding the transient expression assay in $N$. benthamiana leaves. This work was funded by grants from the Spanish Ministerio de Economía y Competitividad (BIO2012-33797), Junta de Andalucía (BIO2012-0474) and by the European Commission Seventh

Framework grant PROCOGEN (FP7-KBBE 2011-5). MBP was supported by a Juan de la Cierva Postdoctoral contract (Ministerio de Ciencia e Innovación, Spain).

Received: 26 June 2015 Accepted: 8 October 2015

Published online: 24 October 2015

References

1. Farjon A. A hadbook of the world's conifers. Leiden: Brill Academic Publishers; 2010

2. Keeling Cl, Bohlmann J. Genes, enzymes and chemicals of terpenoid diversity in the constitutive and induced defence of conifers against insects and pathogens. New Phytol. 2006;170:657-75.

3. Sheard LB, Tan X, Mao H, Withers J, Ben-Nissan G, Hinds TR, et al. Jasmonate perception by inositol phosphate-potentiated COI1-JAZ co-receptor. Nature. 2010;468:400-5.

4. Ralph SG, Yueh H, Friedmann M, Aeschliman D, Zeznik JA, Nelson CC, et al. Conifer defence against insects: microarray gene expression profiling of Sitka spruce (Picea sitchensis) induced by mechanical wounding or feeding by spruce budworms (Choristoneura occidentalis) or white pine weevils (Pissodes strobi) reveals large-scale changes of the host transcriptome. Plant Cell Environ. 2006;29:1545-70

5. Heidel AJ, Baldwin IT. Microarray analysis of salicylic acid- and jasmonic acid-signalling in responses of Nicotiana attenuata to attack by insects from multiple feeding guilds. Plant Cell Environ. 2004;27:1362-73.

6. Koo AJK, Gao X, Jones AD, Howe GA. A rapid wound signal activates systemic synthesis of bioactive jasmonates in Arabidopsis. Plant J. 2009;59:974-86.

7. Aranda I, Alía R, Ortega U, Dantas AK, Majada J. Intra-specific variability in biomass partitioning and carbon isotopic discrimination under moderate drought stress in seedlings from four Pinus pinaster populations. Tree Genet Genomes. 2010;6:169-78.

8. Mackay J, Dean J, Plomion C, Peterson DG, Cánovas FM, Pavy N, et al. Towards decoding conifer mega-genomes. Plant Mol Biol. 2012;80:555-69.

9. Neale DB, Kremer A. Forest tree genomics: growing resources and applications. Nat Rev Genet. 2011:12:111-22.

10. Canales J, Bautista R, Label P, Gomez-Maldonado J, Lesur I, Fernandez-Pozo $\mathrm{N}$, et al. De novo assembly of maritime pine transcriptome: implications for forest breeding and biotechnology. Plant Biotech J. 2014;12:286-99.

11. Rigault $P$, Boyle B, Lepage $P$, Cooke JEK, Bousquet J, Mackay J. A white spruce catalogue for conifer genome analyses. Plant Physiol. 2011;157:14-28. 
12. Seki M, Narusaka M, Ishida J, Nanjo T, Fujita M, Oono $Y$, et al. Monitoring the expression profiles of 7000 Arabidopsis genes under drought, cold and high salinity stresses using a full-length cDNA microarray. Plant J. 2002;31:279-92.

13. Mao X, Jia D, Li A, Zhang H, Tian S, Zhang X, et al. Transgenic expression of TaMYB2A confers enhanced tolerance to multiple abiotic stresses in Arabidopsis. Funct Integr Genomics. 2011;11:445-65.

14. Mao X, Zhang H, Qian X, Li A, Zhao G, Jing R. TaNAC2, a NAC-type wheat transcription factor conferring enhanced multiple abiotic stress tolerances in Arabidopsis. J Exp Bot. 2012;63:2933-46.

15. Mukhopadhyay A, Vij S, Tyagi AK. Overexpression of a zinc-finger protein gene from rice confers tolerance to cold, dehydration, and salt stress in transgenic tobacco. Proc Natl Acad Sci U S A. 2004;101:6309-14.

16. Shen H, Liu C, Zhang Y, Meng X, Zhou X, Chu C, et al. OsWRKY30 is activated by MAP kinases to confer drought tolerance in rice. Plant Mol Biol. 2012;80:241-53.

17. Shinozaki K, Yamaguchi-Shinozaki K, Seki M. Regulatory network of gene expression in the drought and cold stress responses. Curr Opin Plant Biol. 2003;6:410-7.

18. Zhu J. Salt and drought stress signal transduction in plants. Annu Rev Plant Biol. 2002;53:247-73.

19. Olsen AN, Ernst HA, Leggio LL, Skriver K. NAC transcription factors: structurally distinct, functionally diverse. Trends Plant Sci. 2005;10:79-87.

20. Ooka H, Satoh K, Doi K, Nagata T, Otomo Y, Murakami K, et al. Comprehensive analysis of NAC family genes in Oryza sativa and Arabidopsis thaliana. DNA Res. 2003;10:239-47.

21. Souer E, van Houwelingen A, Kloos D, Mol J, Koes R. The no apical meristem gene of Petunia is required for pattern formation in embryos and flowers and is expressed at meristem and primordial boundaries. Cell. 1996;85:159-70

22. Aida M, Ishida T, Tasaka M. Shoot apical meristem and cotyledon formation during Arabidopsis embryogenesis: interaction among the CUP-SHAPED COTYLEDON and SHOOT MERISTEMLESS genes. Development. 1999;126:1563-70.

23. Larsson E, Sundström JF, Sitbon F, von Arnold S. Expression of PaNAC01, a Picea abies CUP-SHAPED COTYLEDON orthologue, is regulated by polar auxin transport and associated with differentiation of the shoot apical meristem and formation of separated cotyledons. Annal Bot. 2012;110:923-34.

24. Sablowski RWM, Meyerowitz EM. A homolog of NO APICAL MERISTEM is an immediate target of the floral homeotic genes APETALA3/PISTILLATA. Cell. 1998:92:93-103.

25. Xie Q, Guo HS, Dallman G, Fang S, Weissman AM, Chua NH. SINAT5 promotes ubiquitinrelated degradation of NAC1 to attenuate auxin signals. Nature. 2002:419:167-70.

26. Lee S, Seo PJ, Lee HJ, Park CM. A NAC transcription factor NTL4 promotes reactive oxygen species production during drought-induced leaf senescence in Arabidopsis. Plant J. 2012;70:831-44.

27. Christiansen MW, Gregersen PL. Members of the barley NAC transcription factor gene family show differential co-regulation with senescence-associated genes during senescence of flag leaves. J Exp Bot. 2014;65:4009-22.

28. Kim YS, Kim SG, Park JE, Park HY, Lim MH, Chua NH, et al. A membrane bound NAC transcription factor regulates cell division in Arabidopsis. Plant Cell. 2006;18:3132-44.

29. Willemsen V, Bauch M, Bennett T, Campilho A, Wolkenfelt H, Xu J, et al. The NAC domain transcription factors FEZ and SOMBRERO control the orientation of cell division plane in Arabidopsis root stem cells. Dev Cell. 2008:15:913-22.

30. Fujita M, Fujita Y, Maruyama K, Seki M, Hiratsu K, Ohme-Takagi M, et al. A dehydration- induced NAC protein, $\mathrm{RD} 26$, is involved in a novel ABA-dependent stress-signalling pathway. Plant J. 2004;39:863-76.

31. Jensen MK, Hagedorn PH, de Torres-Zabala M, Grant MR, Rung JH, Collinge DB, et al. Transcriptional regulation by an NAC (NAM-ATAF1, 2-CUC2) transcription factor attenuates ABA signalling for efficient basal defence towards Blumeria graminis f. sp. hordei in Arabidopsis. Plant J. 2008;56:867-80.

32. Uauy C, Distelfeld A, Fahima T, Blechl A, Dubcovsky J. A NAC gene regulating senescence improves grain protein, zinc, and iron content in wheat. Science. 2006:314:1298-301.

33. Ko JH, Yang SH, Park AH, Lerouxel O, Han KH. ANAC012, a member of the plant-specific NAC transcription factor family, negatively regulates xylary fiber development in Arabidopsis thaliana. Plant J. 2007;50:1035-48.

34. Zhong $\mathrm{R}$, Ye ZH. Transcriptional regulation of lignin biosynthesis. Plant Signal Behav. 2009;4:1028-34.
35. Zhong $\mathrm{R}$, Lee $\mathrm{C}$, Ye Z $\mathrm{H}$. Evolutionary conservation of the transcriptional network regulating secondary cell wall biosynthesis. Trends Plant Sci. 2010;15:625-32.

36. Nakashima K, Takasaki H, Mizoi J, Shinozaki K, Yamaguchi-Shinozaki K. NAC transcription factors in plant abiotic stress responses. Biochim Biophys Acta. 1819;2012:97-103

37. Puranik S, Sahu PP, Srivastava PS, Prasad M. NAC proteins: regulation and role in stress tolerance. Trends Plant Sci. 2012;17:6369-81.

38. Tran LS, Nakashima K, Sakuma Y, Simpson SD, Fujita Y, Maruyama K, et al. Isolation and functional analysis of Arabidopsis stress-inducible NAC transcription factors that bind to a drought-responsive cis-element in the early responsive to dehydration stress 1 promoter. Plant Cell. 2004;16:2481-98.

39. Jensen MK, Lindemose S, de Masi F, Reimer JJ, Nielsen M, Perera V, et al. ATAF1 transcription factor directly regulates abscisic acid biosynthetic gene NCED3 in Arabidopsis thaliana. FEBS Open Bio. 2013;3:321-7.

40. Delessert C, Kazan K, Wilson IW, Van Der Straeten D, Manners J, Dennis ES, et al. The transcription factor ATAF2 represses the expression of pathogenesis-related genes in Arabidopsis. Plant J. 2005;43:745-57.

41. Lu PL, Chen NZ, An R, Su Z, Qi BS, Ren F, et al. A novel drought-inducible gene, ATAF1, encodes a NAC family protein that negatively regulates the expression of stress-responsive genes in Arabidopsis. Plant Mol Biol. 2007;63:289-305

42. Hu H, Mingqiu D, Yao J, Xiao B, Li X, Zhang Q, et al. Overexpressing a NAM, ATAF and CUC (NAC) transcription factor enhances drought resistance and salt tolerance in rice. Proc Natl Acad Sci USA. 2006;103:12987-92.

43. Jeong JS, Kim YS, Redillas MC, Jang G, Jung H, Bang SW, et al. OsNAC5 overexpression enlarges root diameter in rice plants leading to enhanced drought tolerance and increased grain yield in the field. Plant Biotech J. 2013;11:101-14.

44. Duval I, Lachance D, Giguère I, Bomal C, Morency M-J, Pelletier G, et al. Large-scale screening of transcription factor-promoter interactions in spruce reveals a transcriptional network involved in vascular development. J Exp Bot. 2014;65:2319-33.

45. Bailey TL, Williams N, Misleh C, Li WW. MEME: discovering and analyzing DNA and protein sequence motifs. Nucleic Acids Res. 2006;34:369-73.

46. Shen $H$, Yin $Y$, Chen $F, X u Y$, Dixon RA. A Bioinformatic analysis of NAC genes for Plant Cell Wall development in relation to lignocellulosic bioenergy production. Bioenerg Res. 2009;2:217-32.

47. Kim SG, Kim SY, Park CM. A membrane-associated NAC transcription factor regulates salt-responsive flowering via FLOWERING LOCUS T in Arabidopsis. Planta. 2007;226:647-54.

48. Kubo M, Udagawa M, Nishikubo N, Horiguchi G, Yamaguchi M, Ito J, et al. Transcription switches for protoxylem and metaxylem vessel formation. Genes Dev. 2005;19:1855-60.

49. Mitsuda N, Seki M, Shinozaki K, Ohme-Takagi M. The NAC transcription factors NST1 and NST2 of Arabidopsis regulate secondary wall thickenings and are required for anther dehiscence. Plant Cell. 2005;17:2993-3006.

50. Zhong R, Demura T, Ye ZH. SND1, a NAC domain transcription factor, is a key regulator of secondary wall synthesis in fibers of Arabidopsis. Plant Cell. 2006;18:3158-70

51. Aida M, Ishida T, Fukaki H, Fujisawa H, Tasaka M. Genes envolved in organ separation in Arabidopsis: an analysis of the cup-shaped cotyledon mutant. Plant Cell. 1997;9:841-57.

52. Takada S, Hibara K-i, Ishida T, Tasaka M. The CUC-SHAPED COTYLEDON1 gene of Arabidopsis regulates shoot apical meristem formation. Development. 2001;128:1127-35.

53. Vroemen CW, Mordhorst AP, Albrecht C, Kwaaitaal MA, de Vries SC. The CUP-SHAPED COTYLEDON3 gene is required for boundary and shoot meristem formation in Arabidopsis. Plant Cell. 2003;15:1563-77.

54. Kim JH, Woo HR, Kim J, Lim PO, Lee IC, Choi SH, et al. Trifurcate feedforward regulation of age-dependent cell death involving miR164 in Arabidopsis. Science. 2009;323:1053-7.

55. Hussey SG, Mizrachi E, Spokevicius AV, Bossinger G, Berger DK, Myburg AA. SND2, a NAC transcription factor gene, regulates genes involved in secondary cell wall development in Arabidopsis fibres and increases fibre cell area in Eucalyptus. BMC Plant Biol. 2011;11:173.

56. Higo K, Ugawa Y, Iwamoto M, Korenaga T. Plant cis-acting regulatory DNA elements (PLACE) database. Nucleic Acids Res. 1999;27:297-300.

57. Kim SR, Choi JL, Costa MA, An G. Identification of G-box sequence as an essential element for methyl jasmonate response of potato proteinase inhibitor II promoter. Plant Physiol. 1992;99:627-31. 
58. Boter M, Ruiz-Rivero O, Abdeen A, Prat S. Conserved MYC transcription factors play a key role in jasmonate signaling both in tomato and Arabidopsis. Genes Dev. 2004;18:1577-91.

59. Dombrecht B, Xue GP, Spraque SJ, Kirkegaard JA, Ross JJ, Reid JB, et al, MYC2 differentially modulates diverse jasmonate-dependent functions in Arabidopsis. Plant Cell. 2007;19:2225-45.

60. Montiel G, Zarei A, Korbes AP, Memelink J. The Jasmonate-responsive element from the ORCA3 promoter from Catharanthus roseus is active in Arabidopsis and is controlled by the transcription factor AtMYC2. Plant Cell Physiol. 2011:52:578-87.

61. Wang R, Guan P, Chen M, Xing X, Zhang Y, Crawford NM. Multiple Regulatory Elements in the Arabidopsis NIA 1 Promoter Act Synergistically to Form a Nitrate Enhancer. Plant Physiol. 2010;154:423-32.

62. Liu W, Mazarei M, Rudis MR, Fethe MH, Stewart Jr CN. Rapid in vivo analysis of synthetic promoters for plant pathogen phytosensing. BMC Biotech. 2011;11:108.

63. Carretero-Paulet L, Galstyan A, Roig-Villanova I, Martinez-Garcia JF, BilbaoCastro JR, Robertson DL. Genome wide classification and evolutionary analysis of the bHLH family of transcription factors in Arabidopsis, poplar, rice, moss and algae. Plant Physiol. 2010;153:1398-412.

64. Todd AT, Liu E, Polvi SL, Pammett RT, Page JE. A functional genomics screen identifies diverse transcription factors that regulate alkaloid biosynthesis in Nicotiana benthamiana. Plant J. 2010:62:589-600.

65. De Boer K, Tilleman S, Pauwels L, Bossche RV, De Sutter V, Vanderhaeghen $R$, et al. APETALA2/ETHYLENE RESPONSE FACTOR and basic helix-loop-helix tobacco transcription factors cooperatively mediate jasmonate-elicited nicotine biosynthesis. Plant J. 2011;66:1053-65.

66. Liu Y, Schiff M, Dinesh-Kumar SP. Virus-induced gene silencing in tomato. Plant J. 2002;31:777-86.

67. Harfouche A, Meilan R, Altman A. Molecular and physiological responses to abiotic stress in forest trees and their relevance to tree improvement. Tree Physiol. 2014;34:1181-98.

68. Rensing SA, Lang D, Zimmer AD, Terry A, Salamov A, Shapiro H, et al. The Physcomitrella genome reveals evolutionary insights into the conquest of land by plants. Science. 2008;319:64-9.

69. Rushton PJ, Bokowiec MT, Han S, Zhang H, Brannock JF, Chen X, et al. Tobacco transcription factors: novel insights into transcriptional regulation in the Solanaceae. Plant Physiol. 2008;147:280-95.

70. Hu R, Qi G, Kong Y, Kong D, Gao Q, Zhou G. Comprehensive analysis of NAC domain transcription factor gene family in Populus trichocarpa. Plant Biol. 2010;10:145.

71. Nuruzzaman M, Manimekalai R, Sharoni AM, Satoh K, Kondoh H, Ooka H, et al. Genome-wide analysis of NAC transcription factor family in rice. Gene. 2010;465:30-44.

72. Nuruzzaman M, Sharoni AM, Satoh K, Kondoh H, Hosaka A, Kikuchi S. A genome-wide survey of the NAC transcription factor family in monocots and eudicots, in Introduction to Genetics - DNA Methylation, Histone Modification and Gene Regulation (Hong Kong: iConcept Press), 2012a; ISBN 978-14775549-4-4

73. Le DT, Nishiyama R, Watanabe Y, Mochida K, Yamaguchi-Shinozaki K, Shinozaki K, et al. Genome-wide survey and expression analysis of the plant-specific NAC transcription factor family in soybean during development and dehydration stress. DNA Res. 2011;18:263-76.

74. Hussey SG, Saïdi MN, Hefer CA, Myburg AA, Grima-Pettenati J. Structural, evolutionary and functional analysis of the NAC domain protein family in Eucalyptus. New Phytol. 2014;206:1337-50.

75. Rueda-López M, García-Gutiérrez A, Cánovas FM, Ávila C. The family of Dof transcription factors in pine. Trees. 2013;27:1547-57.

76. Lijavetzky D, Carbonero P, Vicente-Carbajosa J. Genome-wide comparative phylogenetic analysis of the rice and Arabidopsis Dof gene families. BMC Evol Biol. 2003;3:17.

77. Pérez-Rodríguez P, Riaño-Pachón DM, Guedes Corrêa LG, Rensing SA, Kersten B, Mueller-Roeber B. PInTFDB: updated content and new features of the plant transcription factor database. Nucl Acids Res. 2010;38:D822-7.

78. Oliveira TM, Cidade LC, Gesteira AS, Coelho Filho MA, Soares Filho WS, Costa MGC. Analysis of the NAC transcription factor gene family in citrus reveals a novel member involved in multiple abiotic stress responses. Tree Genetics Genom. 2011;7:1123-34

79. Taoka K, Yanagimoto Y, Daimon Y, Hibara K, Aida M, Tasaka M. The NAC domain mediates functional specificity of CUP-SHAPED COTYLEDON proteins. Plant J. 2004;40:462-73.
80. Jensen MK, Kjaersgaard T, Nielsen MM, Galberg P, Petersen K, O'Shea C, et al. The Arabidopsis thaliana NAC transcription factor family: Structurefunction relationships and determinants of ANAC019 stress signalling. Biochem J. 2010:426:183-96.

81. Zhang Z-P, Baldwin IT. Transport of [2-14C] jasmonic acid from leaves to roots mimics wound induced changes in endogenous jasmonic acid pools in Nicotiana sylvestris. Planta. 1997;203:436-41.

82. Thorpe MR, Ferrieri AP, Herth MM, Ferrieri RA. 11C-imaging: methyl jasmonate moves in both phloem and xylem, promotes transport of jasmonate, and of photoassimilate even after proton transport is decoupled. Planta. 2007:226:541-51.

83. Collinge M, Boller T. Differential induction of two potato genes, Stprx2 and StNAC, in response to infection by Phytophthora infestans and to wounding. Plant Mol Biol. 2001:46:521-9.

84. Ohnishi T, Sugahara S, Yamada T, Kikuchi K, Yoshiba Y, Hirano HY, et al. OsNAC6, a member of the NAC gene family, is induced by various stresses in rice. Genes Genet Syst. 2005:80:135-9.

85. Nuruzzaman M, Sharoni AM, Kikuchi S. Roles of NAC transcription factors in the regulation of biotic and abiotic stress responses in plants. Front Microbiol. 2013:4:248.

86. Kim SY, Chung HJ, Thomas TL. Isolation of a novel class of bZIP transcription factors that interact with ABA-responsive and embryospecification elements in the Dc3 promoter using a modified yeast onehybrid system. Plant J. 1997;11:1237-51.

87. Kim SY, Thomas TL. A family of novel basic leucine zipper proteins binds to seed-specification elements in the carrot Dc3 gene promoter. J Plant Physiol. 1998;152:607-13.

88. Abe H, Urao T, Ito T, Seki M, Shinozaki K, Yamaguchi-Shinozaki K. Arabidopsis AtMYC2 (bHLH) and AtMYB2 (MYB) function as transcriptional activators in abscisic acid signaling. Plant Cell. 2003;15:63-78.

89. Eulgem T, Rushton PJ, Robatzek S, Somssich IE. The WRKY superfamily of plant transcription factors. Trends Plant Sci. 2000;5:199-206.

90. Brown RL, Kazan K, McGrath KC, Maclean DJ, Manners JM. A role for the GCC-box in jasmonate-mediated activation of the PDF1.2 gene of Arabidopsis. Plant Physiol. 2003;132:1020-32.

91. Patzlaff A, Newman LJ, Dubos C, Whetten RW, Smith C, Mclnnis S, et al. Characterisation of PtMYB1, an R2R3-MYB from pine xylem. Plant Mol Biol. 2003;53:597-608

92. Newman LJ, Perazza DE, Juda L, Campbell MM. Involvement of the R2R3MYB, AtMYB61, in the ectopic lignification and dark-photomorphogenic components of the det3 mutant phenotype. Plant J. 2004;37:239-50.

93. Levée V, Major I, Levasseur C, Tremblay L, MacKay J, Seguin A. Expression profiling and functional analysis of Populus WRKY23 reveals a regulatory role in defense. New Phytol. 2009;184:48-70.

94. Bedon F, Bomal C, Caron S, Levasseur C, Boyle B, Mansfield SD, et al. Subgroup4 R2R3-MYBs in conifer trees: gene family expansion and contribution to the isoprenoid- and flavonoid- oriented responses. J Exp Bot. 2010;14:3847-64.

95. Doyle JJ, Doyle JL. A rapid DNA isolation procedure for small quantities of fresh leaf tissue. Phytochem Bull. 1987;19:11-1596.

96. Canales J, Rueda-López M, Craven-Bartle B, Avila C, Cánovas FM. Novel insights into regulation of asparagine synthetase in conifers. Front Plant Sci. 2012;3:100.

\section{Submit your next manuscript to BioMed Central and take full advantage of:}

- Convenient online submission

- Thorough peer review

- No space constraints or color figure charges

- Immediate publication on acceptance

- Inclusion in PubMed, CAS, Scopus and Google Scholar

- Research which is freely available for redistribution 